Journal of Engineering and Applied Sciences 14 (7): 2268-2271, 2019

ISSN: 1816-949X

(C) Medwell Journals, 2019

\title{
Biopellet Synthesis of Waste Rice Plant (Oryza sativa sp.) as a Environmentally Friendly Alternative Fuel Substance
}

\author{
${ }^{1}$ Wahidin Nuriana and ${ }^{2}$ Praptiningsih Gamawati Adinurani \\ ${ }^{1}$ Department of Mechanical Engineering, \\ ${ }^{2}$ Department of Agricultural, Merdeka University of Madiun, Madiun, Indonesia
}

\begin{abstract}
The abundance of rice straw and rice husks in Indonesia is a potential source of biomass that can be converted into biomass pellet (biopellets). Pelletization can improve the quality and burning characteristic of the biomass. Bio-pellet is an alternative energy that can substituted low grade coal from biomass sources. The purpose of this study is to improve the quality of biopellets. Pellet made with some variation of the biomassa. Biopellet consists of a mixture of the rice straw and husks, the rice straw and bran, the rice husks and bran with a ratio of $1: 1$. The test of biopellet included moisture content, volatile matters, ash, substances, fixed carbon and calorific value. The results showed a mixed type of biomassa affects the characteristics biopellet. Based on the physic chemical properties, biopellet of the husk+bran mixture and the rice straw+bran have better quality than other biopellet. The biopellet of husk+bran has $4138 \mathrm{kcal} / \mathrm{kg}$ of calorific value. The biopellet of the straw + bran have the lowest consumption rate that is $0.60 \mathrm{~kg} / \mathrm{h}$. Additionally, the biopellet of the straw+bran has $3223 \mathrm{kcal} / \mathrm{kg}$ of calorific value.
\end{abstract}

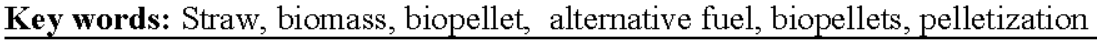

\section{INTRODUCTION}

Energy and food was a basic need for human life, so that, its availability is necessary. The use of fuel energy was increasing rapidly followed by declining availability of fossil fuels. It affects the restriction of subsidized fuel. Therefore, need to look for other sources of fuel especially environmentally friendly renewable fuel. An alternative source of alternative fuels was biomass fuel for agricultural waste because it was easy to obtain, its availability was abundant and could be renewed. The use of biomass fuels sources of agricultural waste was the right choice with the consideration that the majority of Indonesian society is based on the agricultural sector.

From the agricultural sector could be obtained many types of biomass agricultural waste was quite abundant. According to Abdullah (2009) and Bailis et al. (2007) biomass of potential agricultural waste as an alternative energy source include wastes of rice crops (straw, husk), corn waste (cobs, stems, leaves), waste palm (shell, fiber, empty bunches), peanut shells soil, bagasse sugarcane, coconut waste (coir, shell, leaf) and soybean stover. Among the agricultural wastes, rice straw biomass is available in considerable amounts compared to other agricultural wastes. This was also supported by the increase of rice production from year to year (Fig. 1), so that, the rice plant waste also increased (Bassam and Maegaard, 2004).

Rice production in Indonesia in 2012 was $69.06 \mathrm{mln}$. tons of Grain Dried Milleed (GDM) and in 2013 the temporary figure is about $71.29 \mathrm{mln}$. tons of GDM (Anonymous, 2014). According to Prihandana and Hendroko (2007) that the ratio between grain weight and grain straw ratio during harvest was generally between 2-3. In grain milling, husk waste was produced about 20 and $10 \%$ of bran according to Haryadi. Based on the data of grain dried milled production from rice harvest year 2012-2013 (Table 1) could be produced average of straw waste about 105.27 , husk 14.04 and bran $7.02 \mathrm{mln}$. tons/year that was potentially as alternatives fuel.

Biomass could be used as fuel for cooking or other thermal processes. The potential of biomass energy in Indonesia was estimated to be $49.810 \mathrm{MW}(50 \mathrm{GW})$ derived from various biomass of agricultural, forestry, plantation and solid waste or municipal waste. According to Sudrajat (1984) that the biomass potential ranks second after water potential. But the realization as a power plant only reached $445 \mathrm{MW}$ or about $0.89 \%$. As a fuel, biomass still has sufficient calorific value and when used as pellets and gasified will produce high energy output (Kusumaningrum and Munawar, 2014).

Corresponding Author: Wahidin Nuriana, Department of Mechanical Engineering, Merdeka University of Madiun, Madiun, Indonesia 


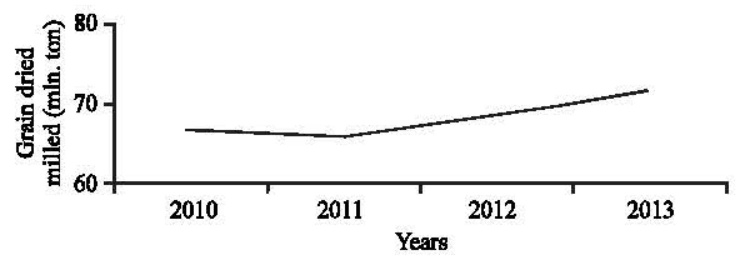

Fig. 1: Production of unhusked rice mill in Indonesia

Table 1: Production of Dry Milled Grain (DMG) and wastewater biomass of rice plants (million tones)

\begin{tabular}{lllll}
\hline Years & Dried paddy* & Straw & Husk & Bran \\
\hline 2012 & 69.06 & 103.59 & 13.81 & 6.91 \\
2013 & 71.29 (ASEM) & 106.94 & 14.26 & 7.13 \\
\hline *Not milled yet
\end{tabular}

So far, agricultural biomass was still regarded as a waste that has no economic value and was often destroyed by burning. It seems that biomass has not been fully utilized. In China, straw biomass was partly used directly as fuel. Its use per capita of $146 \mathrm{~kg} /$ year (Ramsay, 1982) meanwhile in Indonesia, straw and chaff was used as fuel for burning bricks or pottery in boilers and also for household energy purposes. According to Saptoadi (2011) the use of biomass as fuel directly there were weaknesses in physical properties such as low energy density and handling, storage or transportation problems. To overcome these problems could be by making biomass in a more practical form that was a solid form called a pellet (biopellet).

Pelletization was a process of drying and biomass formation using high pressure to produce cylindrical solid biomass. This process aims to produce biomass fuel with a smaller volume and higher energy density. This pellet form facilitates the storage, transportation and conversion into electrical energy or other chemical energy more efficient (Ramsay, 1982).

Biopelet was one form of biomass energy and was first produced in Sweden in 1980 made from raw wood powder which was industrial waste (Nugrahaeni, 2008). In some countries in Europe such as Germany, Canada and Austria already use wood waste biopelet as industrial boiler fuel and space heater during Winter. Biomass in pellet form could be used directly as solid fuel. The advantages of biopellet as fuel include high density, easy in storage and handling. Solid fuel (biopelet) was quite efficient and environmentally friendly. Biopellets could also function as fuel substitutes for kerosene or gas. The existence of biopellet would became a solution to overcome the scarcity of fuel especially in villages or coastal areas. In an effort to explore the potential of biomass of agricultural waste as an environmentally friendly alternative fuel, it is necessary to improve the quality of biopellet production to produce biomass fuel with optimal combustion performance.

\section{MATERIALS AND METHODS}

Experimental section: Biopelet production using crusher machine with capacity of $30 \mathrm{~kg} / \mathrm{h}$ and moulding machine with a capacity of $20 \mathrm{~kg} / \mathrm{h}$. The process begins with the sorting of raw materials. The raw materials used were agricultural waste especially rice plants in this case was straw. Then drying or drying under the Sun. The dried straw was put into a crusher machine for size reduction followed by mixing of raw materials of rice crops (chopped straw, husks and bran). Percentage of mixture of two types of biomass $50 \%$, i.e., straw+bran, straw+husk and husk + bran. As an additive was a $5 \%$ tapioca solution. The mixture of the material was inserted into the biopellet moulding machine. Biopellets are produced in the sun or dried under the sun. Before applied to biomass stoves, the characteristics of the biopellet were first measured, including the specific gravity, moisture content, ash content, volatile, calorific value and bound carbon content of the biopellet.

Biopelet performance test was performed using UB-03 biomass stove. These stoves were fueled by biomass such as small pieces of wood or wasted branches, corncobs, biomass pellets and so on. Biomass stoves are very efficient because they use turbulent combustion systems which could save up to $80 \%$ of biomass usage compared to other stoves using firewood. The performance test uses the Water Boiling Test (WBT) method. Water boiling test was a rough simulation method of a cooking process that could be used to find out how well the heat energy was transferred to the cookware (Anonymous, 2014). With WBT method could be measured the rate of fuel consumption and combustion efficiency.

\section{RESULTS AND DISCUSSION}

Biopellet characteristics: Production of 4 kinds of biopellets from raw materials of rice plants (straw, husk, bran) was presented in Fig. 2 .

Of the three mixed biopellets, it appears that biopelets with extra bran have higher density and denser perfomes. This was because the added bran had a smaller size than the size of the husk. The addition could increase the biopellet density because the cavity between the straw particles arrangement was filled by the smaller bran particle size, thus, increasing the biopelet mass per unit volume. The results of the physicochemical biopellet properties were listed in Table 2 .

Water content: The lowest average biopellet water content in straw was $0.31 \%$. This was due to straw 


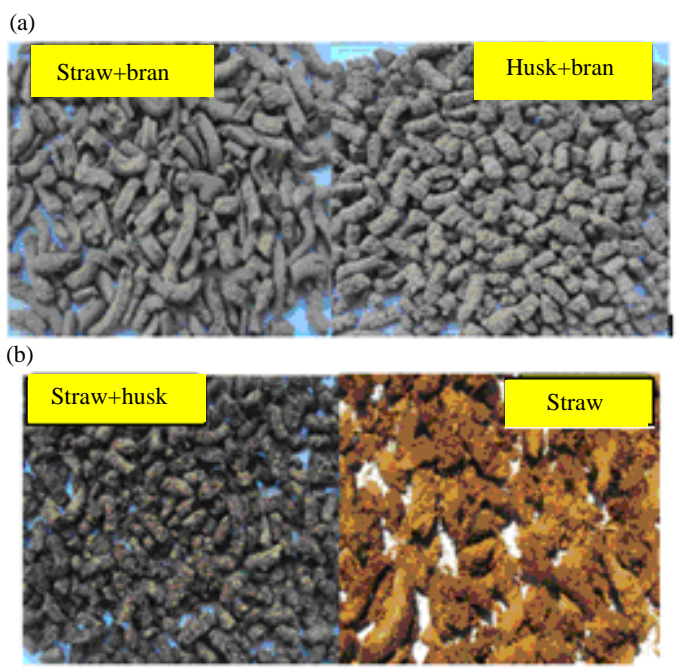

Fig. 2: a, b) Biopelet mixed biomass of rice plant waste

\begin{tabular}{|c|c|c|c|c|c|}
\hline Biopellet & $\begin{array}{c}\text { Water } \\
\text { content } \\
(\%)\end{array}$ & $\begin{array}{l}\text { Ash } \\
\text { content } \\
(\%)\end{array}$ & $\begin{array}{c}\text { Volatile } \\
(\%)\end{array}$ & $\begin{array}{c}\text { Bond } \\
\text { carbon } \\
(\%)\end{array}$ & $\begin{array}{c}\text { Calorific } \\
\text { value } \\
(\mathrm{kcal} / \mathrm{kg})\end{array}$ \\
\hline Straw & 0.31 & 36.50 & 25.14 & 38.37 & 3123 \\
\hline Straw+Bran & 2.12 & & 17.32 & 51.48 & 3322 \\
\hline Straw+Husk & 1.59 & 29.59 & 30.32 & 40.08 & 3220 \\
\hline Husk+Bran & 1.68 & 23.72 & 25.41 & 50.87 & 4138 \\
\hline
\end{tabular}

biopellet more porous than mixed biopellet, so that, at the time of drying a lot of water was evaporated. Biopellet water content effect on burning calorific value, illumination, combustion power and amount of smoke during combustion (Ramsay, 1982). The ease of burning on straw biopellets was faster than mixed biopellets.

Ash content: The average value of biopellet ash content from rice plant waste was between $23.72-36.49 \%$. The highest value of ash content was ash content from straw biopellet. The amount of ash produced in the combustion process was influenced by the type of biopellet raw material. Straw biopellet contains more silica than straw mixed biopelet+bran or straw + husk. The higher the silica content of the biopellet raw material the higher the amount of ash produced. Ash was an undesirable component of the combustion process (Saptoadi, 2006) because it could reduce combustion efficiency (Grover et al., 2002).

Volatile: The number of volatile substances in the biopelet was a parameter to know the amount of smoke produced during the combustion process. The highest volatile content of straw thusk mixed biopelet was $30.32 \%$ while the mixed straw + bran had a volatile of $17.3 \%$. This indicates that the smoke produced during burning more in the strawthusk biopelet because the higher the

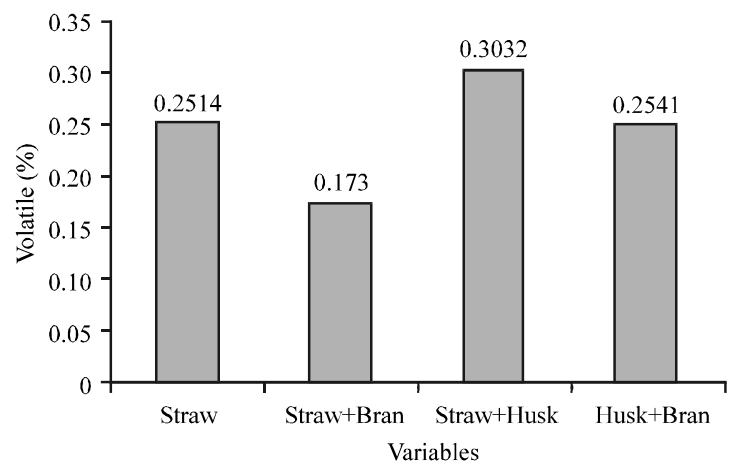

Fig. 3: Volatile substances from rice plant waste biopelet

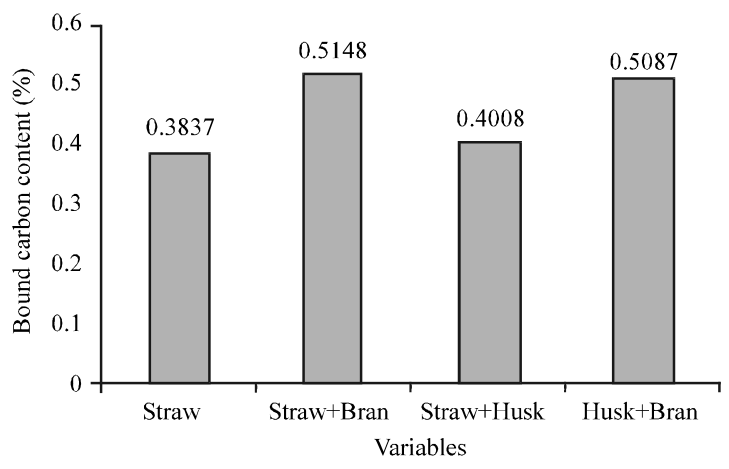

Fig. 4: Bound carbon content of rice plant waste biopellet

volatile percentage in the fuel the higher the amount of smoke produced (Jansen, 2011) and causes the biopelet burning efficiency to decrease (Makarim and Suyamto, 2007) (Fig. 3).

Bound carbon content: The highest bound carbon content on the mixed straw + bran biopelet is $51.48 \%$. This shows that the compacted solid material component in straw+bran biopellet was more than any other biopellet. Bound carbon content was a Carbon (C) fraction present in the biopellet component components other than water, ash and volatile substances so that the carbon values were affected by moisture content, ash and volatile substances (Nurwigha, 2012). The result of carbon value in straw+bran biopellet was supported by lower percentage of water content, ash and volatile than straw thusk biopellet (Fig. 4).

Calorific value: Grover et al. (2002), Hendra and Pari (2000) states that the heating value was a parameter to determine the quality of biomass waste solid fuels. The higher the caloric value could be said the better the fuel quality. The highest heating value was in bran husk biopelet + bran was $4138 \mathrm{kcal} / \mathrm{kg}$, followed by straw + bran biopellet, i.e., $3322 \mathrm{kcal} / \mathrm{kg}$ (Fig. 5). 


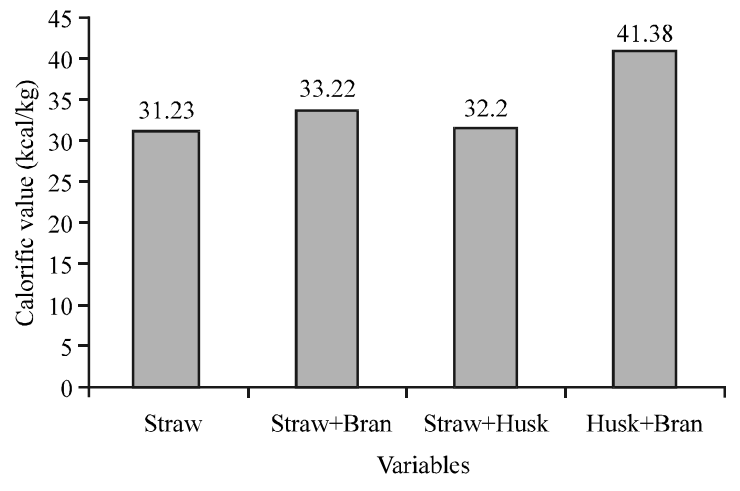

Fig. 5: Calorific value of rice plant waste biopelet

\begin{tabular}{lccc}
\multicolumn{4}{l}{ Table 3: Test rate of consumption of rice plant biopelet } \\
$\begin{array}{lccc}\text { Boiling time of } \\
\text { Biopellet }\end{array}$ & $\begin{array}{c}\text { Used biopellet } \\
\text { mass }(\mathrm{g})\end{array}$ & $\begin{array}{c}\text { Rate of biopellet } \\
\text { consumption (kg/iam) }\end{array}$ \\
\hline Straw & 4 & 70 & 1.05 \\
Straw+Bran & 5 & 50 & 0.60 \\
Straw+Husk & 5.5 & 70 & 0.76 \\
Husk+Bran & 3.8 & 50 & 0.79 \\
\hline
\end{tabular}

Biopelet performance test: Water boiling test results for the four biopelets are listed in Table 3 .

\section{CONCLUSION}

Biopelet of straw mixture+bran and husk+bran have better characteristic than straw or straw biopellet with calorific value 4138 and $3322 \mathrm{kcal} / \mathrm{kg}$. The results of the performance test on straw biopellet + bran have the lowest consumption rate of $0.60 \mathrm{~kg} / \mathrm{h}$.

\section{ACKNOWLEDGEMENTS}

Researchers would like to thank the Directorate of Research and Community Services Directorate General of Higher Education Seminarian Education and Culture of the Republic of Indonesia which has funded this research by number: Number: 019/SP2H /PPM-MONO /K7/KM/2014 dated April 3, 2014.

\section{REFERENCES}

Abdullah, K., 2009. Sustainable parameters in introducing renewable energy technology. ISESCO. Sci. Technol. Vis., 5: 7-10.

Anonymous, 2014. Production of rice, corn and soybean (Figures in 2013). Central Bureau of Statistics (BPS), Jakarta, Indonesia.

Bailis, R., D. Ogle, N. MacCarty, D. Still and R. Edwards et al., 2007. The water boiling test version 3.0: Cook-stove emissions and efficiency in a controlled laboratory. Master Thesis, University of California Berkeley, Berkeley, California.
Bassam, N.E. and P. Maegaard, 2004. Integrated Renewable Energy for Rural Communities: Planning, Guidelines, Technologies and Application. Elsevier, Amsterdam, The Netherlands, Pages: 315.

Grover, V.I., V.K. Grover and W. Hoghland, 2002. Recovering Energy from Waste: Various Aspect. Science Publisher Inc., Enfield Town, England, UK., ISBN:9781578082001, Pages: 338.

Hendra, D. and G. Pari, 2000. Improvement of charcoal processing technology. Forest Products Research and Development Institute, Los Banos, Philippines.

Jansen, T., 2011. Gasification of woody biomass. Master Thesis, University of Twente, Enschede, Netherlands.

Kusumaningrum, W.B. and S.S. Munawar, 2014. Prospect of bio-pellet as an alternative energy to substitute solid fuel based. Energy Procedia, 47: 303-309.

Makarim, A.K. and S. Suyamto, 2007. [Rice straw: Management and utilization]. Master Thesis, Research and Development Centre of Agriculture, Ministry of Agriculture, Bogor, Indonesia.

Nugrahaeni, J.I., 2008. Utilization of tobacco waste (Nicotiana tobacco L.) for brick making materials as alternative fuels. Faculty of Agricultural Technology, Bogor Agricultural University, Bogor, Indonesia.

Nurwigha, N., 2012. Making Biopelet from Palm Oil Shell with the addition of Palm Shell Charcoal and Palm Oil as a Renewable Alternative Material. Bogor Agricultural University, Bogor, Indonesia,

Prihandana, R. and R. Hendroko, 2007. [Green Energy]. Penebar Swadaya Publisher, Jakarta, Inodnesian, Pages: 248 (In Indonasian).

Ramsay, S.W., 1982. Energy from Forest Biomass: XVII IUFRO World Congress Energy Group Proceedings. Academic Press, Cambridge, Massachusetts, USA., ISBN: 9780126527803 , Pages: 279.

Saptoadi, H., 2006. The best biobriquette dimension and its particle size. Proceedings of the 2nd Joint International Conference on Sustainable Energy and Environment (SEE'06), November 21-23, 2006, SEE, Bangkok, Thailand, pp: 1-5.

Saptoadi, H., 2011. Solid fuel from earth Indonesia for Independence and Nation Welfare. Faculty of Engineering, Gadjah Mada University, Yogyakarta, Indonesia.

Sudrajat, R., 1984. Effect of wood density, pressure of forging and type of adhesive on wood briquette properties. J. For. Prod. Res., 1: 11-15. 